\title{
openheart Mechanical circulatory support in CS: device or patient?
}

\author{
Nuccia Morici, ${ }^{1,2}$ Guido Tavazzi (D) ${ }^{3}$
}

To cite: Morici N, Tavazzi G. Mechanical circulatory support in CS: device or patient?. Open Heart 2021;8:e001733. doi:10.1136/ openhrt-2021-001733

Accepted 13 July 2021

\section{SLinked}

- http://dx.doi.org/10.1136/ openhrt-2021-001662

Check for updates

(C) Author(s) (or their employer(s)) 2021. Re-use permitted under CC BY-NC. No commercial re-use. See rights and permissions. Published by BMJ.

${ }^{1}$ SS UTIC/ SC Cardiologia 1-Emodinamica, ASST Grande Ospedale Metropolitano Niguarda, Milano, Lombardia, Italy

${ }^{2}$ Fondazione IRCCS Policlinico S. Matteo, Department of Anesthesia and Intensive Care Unit, Pavia, Italy

${ }^{3}$ Clinical, Surgical, Diagnostic and Pediatric Sciences, University of Pavia, Pavia, Italy

Correspondence to Dr Guido Tavazzi; guido. tavazzi@unipv.it
Cardiogenic shock (CS) is an evolving syndrome due to pump failure and ensuing hypoperfusion as landmark points of the downward spiral leading to multiorgan failure. Among many challenges that need to be addressed, two main critical issues have been coming into focus over the past years: the need for an optimum (early) timing of treatment and a full understanding of an array of 'CS phenotypes', requiring tailored therapies. Indeed, the same cardiac insult, acting on top of pre-existing cardiac or systemic disease, can activate different mechanistic drivers yielding to the formation of distinct shock states. ${ }^{1}$ Whenever is the cause leading to $\mathrm{CS}$, a great emphasis has been recently paid to the protective role of the early mechanical circulatory support (MCS) implantation for stage C-E CS or preceding the revascularisation in patients with acute myocardial infarction (AMI). ${ }^{2}$

There is no strong evidence as yet regarding better safety and outcome among different percutaneous ventricular-assist devices. ${ }^{34}$ The only, reasonable, certainty is that the early institution of an additional device to further offload the struggling ventricle when the veno-arterial extra-corporeal membrane oxygenation (VA-ECMO) is not enough may improve the outcome. ${ }^{56}$

Waqas Ullah and colleagues performed a meta-analysis with the aim to disentangle some of the many uncertainties about the ideal percutaneous support (intra-aortic balloon pump (IABP) vs Impella) in terms of efficacy and safety. ${ }^{7}$ According to their results in the pooled analysis, including three randomised clinical trials (RCT) and four observational registries, the percutaneous ventricular assist device (pVAD) IMPELLA (Abiomed, Danvers, Massachusetts) may significantly decrease the risk of all-cause mortality and the need for repeat revascularisation as compared with
IABP. The mean follow-up was of 3.4 months without statistically significant differences in the rate of stroke, acute limb ischemia and major bleeding events.

Nevertheless, the favourable result in decreasing hard endpoints with IMPELLA device was attenuated in the sensitivity analysis, which did not consider the biggest observational study by Khera et al. Authors should be commended for the effort to make highquality evidence with data available in the literature.

The development and data collection in CS population are extremely challenging, indeed, as underlined by the authors, there is a remarkable paucity of adequately powered randomised trials. Therefore, current knowledge is mainly based on nonrandomised observational studies. Additionally, most of the studies have focused on AMI-related CS although in the current years the different epidemiology and clinical phenotypes of patients with CS are just becoming more evident. $^{89}$

Jeopardization and heterogeneity of patients pathophysiology in previous studies, especially those retrospectively conducted, cannot be excluded as well as interpretation bias.

Considering the relevant uncertainties, redefinition of CS pathophysiology(ies) and the still unacceptably high mortality rate, ${ }^{10}$ one of the relevant questions to address related to percutaneous devices is: Are we looking for the best MCS or for the specific phenotype able to identify patients who are likely to benefit from a tailored support? The need for understanding the underlying pathophysiology and phenotypes has expanded CS taxonomy and given a renew dignity to the use of pulmonary artery catheter, which finds its place only as a goaldirected monitoring system. ${ }^{12}$ Moreover, this paradigm shift has raised another question: what is the best tool for early identifying and monitoring CS patients? May clinical evaluation coupled with mini-invasive approach 
(central venous pressure, central venous saturation and arterial line) and an 'echo-dynamic' diagnostic (indirect estimation of filling pressure, estimation of stroke volume and cardiac output, evaluation of arterial and ventricle elastance, measurements of right ventricle function and pulmonary pressures) improve outcome throughout a tight linkage with therapies of proven benefit (as heart transplantation and durable VAD)? Which is the room for metabolomics and proteomics? Prospective clinical trials are warranted, but they are really tough to set in this setting. Indeed, physicians taking care of patients with CS are lacking clinical equipoise, that is, the genuine uncertainty about the preferred treatment for a patient, because they are overwhelmed by the urgency to do something, something they trust and are confident with.

Large prospective registries can provide complementary and useful information and should be considered the platform in which RCTs can be designed.

The goal of any MCS is to improve 'cellular dysoxia' by increasing myocardial and peripheral perfusion, reducing afterload and decreasing cardiac work. In this perspective, the best treatment has to take into account the starting 'functional' reserve and the adaptive mechanisms which each patient would put in place. To assess and to treat in a sequential escalation guided by all available parameters and within a well-trained team will probably change the stagnant mortality in one of the most severe heart disorders.

\section{Contributors All authors contributed equally.}

Funding The authors have not declared a specific grant for this research from any funding agency in the public, commercial or not-for-profit sectors.

Competing interests None declared.

Patient consent for publication Not required.

Provenance and peer review Commissioned; internally peer reviewed.

Open access This is an open access article distributed in accordance with the Creative Commons Attribution Non Commercial (CC BY-NC 4.0) license, which permits others to distribute, remix, adapt, build upon this work non-commercially, and license their derivative works on different terms, provided the original work is properly cited, appropriate credit is given, any changes made indicated, and the use is non-commercial. See: http://creativecommons.org/licenses/by-nc/4.0/.

ORCID iD

Guido Tavazzi http://orcid.org/0000-0002-9560-5138

\section{REFERENCES}

1 Lawler PR, Mehra MR. Advancing from a "hemodynamic model" to a "mechanistic disease-modifying model" of cardiogenic shock. $J$ Heart Lung Transplant 2018;37:1285-8.

2 Basir MB, Kapur NK, Patel K, et al. Improved outcomes associated with the use of shock protocols: updates from the National cardiogenic shock initiative. Catheter Cardiovasc Interv 2019;93:1173-83.

3 Schrage B, Ibrahim K, Loehn T, et al. Impella support for acute myocardial infarction complicated by cardiogenic shock. Circulation 2019;139:1249-58.

4 Alushi B, Douedari A, Froehlig G, et al. Impella versus IABP in acute myocardial infarction complicated by cardiogenic shock. Open Heart 2019;6:e000987.

5 Russo JJ, Aleksova N, Pitcher I, et al. Left ventricular unloading during extracorporeal membrane oxygenation in patients with cardiogenic shock. J Am Coll Cardiol 2019;73:654-62.

6 Schrage B, Becher PM, Bernhardt A, et al. Left ventricular unloading is associated with lower mortality in patients with cardiogenic shock treated with Venoarterial extracorporeal membrane oxygenation: results from an international, multicenter cohort study. Circulation 2020;142:2095-106.

7 Ullah W, Zghouzi M, Mukhtar M, et al. Comparative safety of percutaneous ventricular assist device and intra-aortic balloon pump in acute myocardial infarction-induced cardiogenic shock. Open Heart 2021;8:e001662.

8 Tehrani BN, Truesdell AG, Psotka MA, et al. A standardized and comprehensive approach to the management of cardiogenic shock. JACC Heart Fail 2020;8:879-91.

9 Berg DD, Bohula EA, van Diepen S, et al. Epidemiology of shock in contemporary cardiac intensive care units. Circ Cardiovasc Qual Outcomes 2019;12:e005618.

10 Shah M, Patnaik S, Patel B, et al. Trends in mechanical circulatory support use and hospital mortality among patients with acute myocardial infarction and non-infarction related cardiogenic shock in the United States. Clin Res Cardiol 2018;107:287-303.

11 van Diepen S, Katz JN, Albert NM, et al. Contemporary management of cardiogenic shock: a scientific statement from the American heart association. Circulation 2017;136:e232-68.

12 Garan AR, Kanwar M, Thayer KL, et al. Complete hemodynamic profiling with pulmonary artery catheters in cardiogenic shock is associated with lower in-hospital mortality. JACC Heart Fail 2020;8:903-13. 